\title{
Boosting Research for Health in Libya and Developing Countries. Research Incubtors
}

\author{
Aisha Nasef ${ }^{1 *}$ and Adel El Taguri ${ }^{2}$ \\ Authority of Natural Science Research and Technology, Libya \\ ${ }^{2}$ National Center for Accreditation of Health Establishments, France
}

\author{
Received: 30 February, 2020 \\ Accepted: 18 April, 2020 \\ Published: 20 April, 2020
}

*Corresponding author: Aisha Nasef, Authority of Natural Science Research and Technology, Libya, Tel: +218 910419 561; E-mail: nasef@doctor.com

Keywords: Research; Incubators; RIS; Libya; Health; BMRIs; INSERM

https://www. peertechz.com

Check for updates

\section{Introduction}

Research is a search for knowledge and an attempt to find out in a systematically and scientific manner to establish facts. It is characterized by clarity, objectivity, precision, validation, verification and generalizability.

Each community has its own specific health problems to which national medical research could help in finding solutions. In Libya, the economic status permit conduction of research as compared to other Arabic countries with relative availability of some resources needed as infrastructure (building, equipment's) and supplies. Unfortunately, it is the culture of medical research that is lacking. Many medical graduates from Libya are first introduced to research culture and do their first research while they are abroad for postgraduate studies. Although, many obtained their doctorate degree, but only few had published a high impact article. Although we noticed that young graduates are very motivated to do research, the research environment is not yet suitable in most of our educational establishments.

Libyan biomedical research are scanty. Analysis of Libyan medical publication in 1996-2005, showed that Libya did not appear in the top 20 of African biomedical publication and appear $12^{\text {th }}$ in annual Arabic medical publication and situated behind countries with low Gross Domestic Product (GDP) such as Yemen and Morocco $[1,2]$.

The main obstacle can be defined by lack of attitude with lack of national strategy and planning at stakeholder's level, and by lack of knowledge and competency at researcher level. Currently, the educational and research facilities in the country are below the required standards in each determinant. However, this obstacle could be overcome by providing proper training and standards setting along with accountability and wise use of resource.

The challenges and the opportunities as well as the possible interventions that could improve the Libyan medical research culture and outcomes has been discussed [3]. One of the most promising suggestion was the solicitation of adoption of biomedical research incubators concepts [4], in proposal submitted to the president of Tripoli University in 2013, in an attempt to establish and enhance quality research culture.

Biomedical Research Incubators (BMRIs) are a specialized research unit in one of research topic in the medical, biomedical, or pharmaceutical field. BMRIs could play different roles as a germinator or incubator or accelerator. As germinators, they act as promoters of new ideas that represent "pre-projects" and develop it to start new projects that continue or develop current or past work. BMRIs could actively seek financial, technical and scientific partnership to execute sound projects [5]. BMRIs provide expertise and resources to fill the gap between different research laboratories to produce high quality research $[6,7]$. As accelerators, BMRIs could help to translate research developed in these incubators into industry [5].

BMRIs could lead to natural clustering and collaboration, where researchers could learn more from each other to keep research programs sustainable and independent ensuring thus high quality research [8. However, BMRIs could face challenges such access to appropriate support services and professional networking.

Business incubators providing the networks, expertise 
and needed tools [9]. It's characterized by managed work space, providing shared facilities, advisory, training and financial services, and a nurturing environment. Incubators have different models; according to mandate (profit or nonprofit), the type of sponsorship (public, private or mixed) and focus (mixed, use or niche). Niche incubators are related to bio-technology (bio-incubators), and they prolong survival rates for more than 50-70 percent (9). This could signify the usefulness of incubators, where BMRIs could play comparable crucial rule in health promotions.

In health and medical research, we could set the French Institute of Health and Medical Research (INSERM) as a very early example of BMRIs. It's a public scientific and technological institute founded in 1964, dedicated for biomedical research and health, and committed to scientific challenges and progress in health and medical research. It works to advance knowledge of diseases, treatment and public health by bringing all stakeholders (researchers, technicians, engineers and administrative staff) around one common goal to improve health for all. It involves entire range of activities from the laboratory to the patient's bedside and partners with world prestigious institutions [10].

In our opinion, BMRIs could be designed to work according to principles of; Initiative, Independence, Inclusion, Partnership and knowledge exchange with all public and private partners and stakeholders (Ministry of health, medical institutions and centers, medical universities and faculties, related ministries, local and international organization and others stakeholders). Fair and comprehensive geographical distribution in Libya is highly advisable. Specific activities should be developed and implemented by BMRIs in order to meet the needs of the Libyan national strategy and plans, where BMRIs could help in specified domains. These could include incubators for Cancers and histopathology; Child Health; Nutrition; Epidemiology and screening; Chronic non-communicable diseases; Infectious disease and HIV; Health policy; Medical insurances; Health reform; Pharmacology and drugs; Clinical and applied research; Basic research; Hematology; Rheumatology; Cardiology; Respiratory diseases; Immunology; Digestive diseases; Neurological diseases; Endoscopic surgery; Musculoskeletal diseases; Regenerative medicine; Medical technology; Geriatrics; Genetic diseases; Women health; Medical education; health and environment; etc. For nomenclature of research incubators, we could use first two letters form the specialty of the BMRIs, and to number it according to the order of the city in the country. Examples of nomenclature of Child Health Research Incubator in Tripoli, we label it (CHRI-1), in Benghazi (CHRI-2) and in Misurata city: (CHRI-3), etc. For Epidemiology and Screening Research Incubator in Tripoli city (ESRI-1), In Benghazi city (ESRI -2) and in Misurata city (ESRI -3), etc.

The goals and missions of BMRIs are summarized in Text. Box. 1 and Text. Box. 2.

\section{Text. BOX. 1: GOALS OF BMRIs.}

1. Establishment of strategic partnerships in health sector between governmental, professional, academic and innovation

2. Enhancement of scientific research conduction and publication in health sector.

3. Engagements of larger number of researcher through establishments of accessible research incubators in different medical specialties.

4. Providing a body permit integration of academic and clinical research.

5. Acting as an experience house that could provide advice and support for evidence based decisions in different medical and health specialties.

Text-box 2: MISSION OF BMRIs.

1. Production of state of art researches that could be used for policy making by stakeholders.

2. Providing accredited postgraduate academic studies (Master and Ph.D.) by collaboration through higher education institutes and medical centers and ministry of health and related sectors.

3. Graduation of competent researchers that could be work as a lifelong researcher.

4. Development of medical universities system for academic and teaching staff promotion.

5. Assessment of status of medical, paramedical, pharmaceutical and biomedical services for continuous development.

6. Ease identification of needs, follow-up and development of each incubator in all medical specialties.

7. Provide accessibility of technical, financial and scientific support in specified topic according to specialty. Provide co-working spaces, conference rooms, labs, technical and mentoring staff, concierge services.

8. Reduction of expenses and increase of cost effectiveness through shared and wise use of complementary available resource.

9. Provide a suitable environment for graduation of competent researcher in postgraduate and higher education.

10. Provide training, resources, and the physical infrastructure essential to fostering scientific exploration.

11. Collaborate with academic incubators to prepare the university's student with academic degree, and to launch business, develop new product and to retain entrepreneurial students and researchers.

12. Assessment of scientific research progress, agreement, contracts and providing of suggestion and scientific opinions.

13. Follow-up with all stakeholders.

\section{Conclusion}

Incubator-incubation research concept started since more than 35 years, and has been studied thoroughly by Hackett and Dilts [11]. They discussed epistemological evolution of incubators incubation concepts, and innovation and outcomes of incubates.

Although a developing country, Libya is capable of establishing a good medical research culture. Bringing all stakeholders together to contribute to national, regional and possibly in near future in international health is very essential. This could be done through adoption of BMRIs strategy by decision makers. Studies on incubators process, development, configuration, and possible outcomes and impact of success of incubation are urgently needed to encourage adoption of incubators-incubation environment model.

\section{References}

1. Tadmouri GO, Bissar-Tadmouri N (2003) Biomedical publications in an unstable region: the Arab world, 1988-2002. Lancet 362: 1766. Link: https://bit.ly/2XJVvzd

2. Ahmed MO, Velkinburgh JC, Daw MA (2018) Analysis of biomedical 
publications in Libya from 2003 to 2013. Letter to the Editor 31: 187-188. Link: https://bit.ly/34K1ndf

3. Nasef $A$ (2020) Challenges and opportunities of medical research in Libya. ACMPH 6: 28-30. Link: https://bit.ly/2Vj11XL

4. Alba M, Jorge E, Duque M, Manuel E (2014) The Role of Research Incubators in Encouraging Research and Publication Among Medical Students. Letter to the Editor 89: 961-962. Link: https://bit.ly/2RQekgq

5. United Nations Research Institute for Social development. UNRISD. Link: https://bit.ly/2yqk7Ce

6. Davies M (2009) Mixed-use Incubator Handbook: A Start-up Guide for Incubator Developers. Link: https://bit.ly/34lzqCD
7. Link: https://bit.ly/2VgplUT

8. Link: https://bit.ly/2xuJeUI

9. Scaramuzzi E (2002) Incubators in Developing Countries: Status and Development Perspectives. infoDev Program. Link: https://bit.ly/2RPohe1

10. Link: https://bit.ly/3exUKzh

11. Hackett SM, Dilts DM (2004) A Systematic Review of Business Incubation Research. J Technol Transf 29: 55-82. Link: https://bit.ly/2Kd3MU6

Discover a bigger Impact and Visibility of your article publication with Peertechz Publications

\section{Highlights}

* Signatory publisher of ORCID

* Signatory Publisher of DORA (San Francisco Declaration on Research Assessment)

* Articles archived in worlds' renowned service providers such as Portico, CNKI, AGRIS, TDNet, Base (Bielefeld University Library), CrossRef, Scilit, J-Gate etc.

* Journals indexed in ICMJE, SHERPA/ROMEO, Google Scholar etc.

* OAI-PMH (Open Archives Initiative Protocol for Metadata Harvesting)

* Dedicated Editorial Board for every journa

* Accurate and rapid peer-review process

* Increased citations of published articles through promotions

* Reduced timeline for article publication

Submit your articles and experience a new surge in publication services (https://www.peertechz.com/submission).

Peertechz journals wishes everlasting success in your every endeavours.

Copyright: (C) 2020 Nasef A, et al. This is an open-access article distributed under the terms of the Creative Commons Attribution License, which permits unrestricted use, distribution, and reproduction in any medium, provided the original author and source are credited. 